\title{
Study on the Application of Smart Water System in Urban Water Supply
}

\section{Yao Fengchun}

Water Supply Bureau of Shandong Yellow River Bureau, Jinan, China

\section{Email address:}

122703986@qq.com

\section{To cite this article:}

Yao Fengchun. Study on the Application of Smart Water System in Urban Water Supply. Science Innovation. Vol. 9, No. 4, 2021 , pp. 176-178. doi: 10.11648/j.si.20210904.22

Received: May 20, 2021; Accepted: June 25, 2021; Published: July 9, 2021

\begin{abstract}
The construction of intelligent water system can realize the rational application purpose of urban water resources, and also can improve the level and quality of water service. In this system, by combining information resource system with intelligent management system, it provides data information for management staff, which is conducive to more scientific management and ensures the good application of intelligent water system in urban water supply system. This paper analyzes the application of intelligent water system in urban water supply, including the importance of intelligent water system, the key points of system construction and suggestions for effective application, and gives priority to the important influence and value of intelligent water system. Then, it explores how to build and apply intelligent water system, and tries to make every effort to make in-depth and comprehensive analysis, It provides theoretical reference for relevant enterprises and staff to practice and apply the system, and ensures better application of the system, so as to promote the good development of urban water supply. It is hoped that the discussion in this paper can provide a powerful help for the further promotion of intelligent water system in urban water supply system.
\end{abstract}

Keywords: Smart Water System, Urban Water Supply, Application, Research

\section{智慧水务系统在城市供水中的运用研究}

\section{姚逢春}

山东黄河河务局供水局, 济南市, 中国

\section{邮箱}

122703986@qq.com

摘要：智慧水务系统的建设，能实现对城市水资源的合理应用目的，也能提搞水务服务水平与质量。在该系统中，通 过把信息资源系统与智慧管理体系结合，为管理工作人员提供数据信息，利于更加科学进行管理，保证智慧水务系统 在城市供给水系统良好的应用。本文分析智慧水务系统在城市供水中的运用相关内容，包括智慧水务系统的重要性以 及系统建设要点以及有效应用的建议, 优先肯定智慧水务系统发挥重要影响与价值, 后探索如何构建和应用智慧水务 系统, 力求通过深入和全面分析, 为相关企业以及工作人员实践和应用该系统, 提供理论参考依据, 确保更好应用该 系统, 以此促进城市供水作业良好开展。希望通过本文的论述能为智慧水务系统在城市供水系统中进一步推广提供有 力帮助。

关键词: 智慧水务系统, 城市供水, 运用, 研究 


\section{1. 引言}

随着我国社会的发展, 经济的繁荣, 城市化建设也正 在加快进程。原有城市供水模式已不能适应现阶段城市供 水的需求。保证人民的用水安全, 提高供水总体效益, 是 目前各供水企业需要重点解决的主要问题[1]。新形势下, 城市供水管理体系应用全新的科学技术，如传感技术、物 联网技术以及云计算技术等新型技术。各类新型技术的应 用构建一个全新的水务体系—智慧水务系统, 该系统以 新型技术作为保障, 有效把城市供水中的水厂以及供水管 理部门与供水等有效进行连接, 也把各个水设施有效的连 接, 利于水务系统更好的运行, 提高水务工作以及办事的 效率，提升整个水务业务的服务质量和水平，为水务企业 以及城市的良好发展作保障[2]。因此, 建议在当下以及未 来积极主动构建智慧水务系统, 在城市供水中进一步推广 并应用智慧水务系统[3]。

\section{2. 智慧水务系统的重要性}

\section{1. 营造良好水务行业投资环境}

智慧水务系统的建设, 改善和优化水务行业市场投资 环境, 吸引各方对智慧水务系统的研究, 通过智慧水务系 统的建设和应用, 进一步强化水务服务质量, 营造良好的 水务行业投资环境[4]。这样，不但增加了城市的招商引资 机会, 还为现代化城市、信息化城市等建设和发展打下坚 实的基础[5]。

\section{2. 提升水务企业综合实力与竞争力}

尝试建设智慧水务系统的企业, 提高自身核心竞争力 以及综合实力, 其在税务系统建设期间, 引进各类新型科 学技术, 构建智能化税务系统, 为用户提供更加高质的服 务, 加快水务企业的经济发展, 使其更好在市场中生存和 发展 $[6]$ 。

\section{3. 促进城市化的进一步发展}

智慧水务系统的构建与应用, 实现对各类资源优化与 整合应用，提高税务服务的质量与效率，该系统应用供水 智慧管理体系和信息资源体系, 改变以往的被动供水作业 的模式, 利用主动和智能化模式进行服务, 降低水务管理 工作难度, 一定程度上促进城市的发展, 加快其现代化发 展步伐[7]。

\section{3. 智慧水务系统的构建要点}

\section{1. 智慧水务系统平台的建设}

智慧水务系统的建设，应涵盖基础的实施层以及数据 服务层与框架平台秤、实践应用层等不同体系构成。在不 同层建设中, 均需要体现智慧水务服务特点, 确保系统中 具备丰富的通讯资源、网络资源以及服务器资源等, 也要 保证智慧水务层具备数据存储以及分析的功能、运算分析
以及数据展示等功能, 这样利于获取完善数据信息, 更加 高效作出决策。

\section{2. 智慧水务系统平台功能}

智慧水务系统平台的功能应全面, 如, 要包括客户的 服务功能、数据采集以及集中管理等功能。客户服务功能 可以协助客户, 结合其需求建设关系数据库平台, 利于促 进客户生命周期的管理, 也可以实现客户信息的良好关联, 利于企业对客户信息的进一步管理, 结合客户信息判断其 需求, 为客户提供更加方便以及主动和个性化的服务。数 据采集以及集中管理功能, 可把物联网以及云计算等作为 技术支撑，利用各个新型技术采集数据信息、进行建模和 调度、对数据分析, 或者利用GIS技术进行查询以及分析 和运维工等工作结合, 利于实现智慧服务以及集中化管理 [8]。

\section{3. 智慧水务平台的特色}

智慧水务平台特点体现在模块化以及云服务等方面, 且可以结合自身的需求详细进行规划或者分布进行实施, 利于借助当下公有云以及私有云和混合云等建设良好运 行环境, 利于智能化运行和应用税务平台系统。与此同时, 智慧水务系统的建设, 可以通过应用数据建模的模式, 进 一步扩展业务, 使得平台的应用更加灵活和方便。用户能 够结合自身的需求与特点, 来选择 $\mathrm{C} / \mathrm{S}$ 或者 $\mathrm{B} / \mathrm{S}$ 等不同架构, 使得水务平台更加的人性化, 操作更加的便利, 也进一步 增强该平台的开放性, 使其良好与第三方系统良好结合, 更好的对数据信息等进行管理。

\section{4. 智慧水务系统在城市供水中的运用建议}

\section{1. 建设完善供水管理系统}

建设完善、健全的智慧水务系统, 要优先建设供水管 理体系，在该智慧服务平台建设过程中，有限保证可以满 足信息数据资源共享以及视频监控功能等条件和要求, 充 分利用网络技术、数字技术建设数字化供水系统, 利于为 网络服务以及在线业务的办理营造良好环境与氛围, 发挥 水务系统的最大优势, 进一步优化和完善以往供水管理方 式不足, 变被动为主动, 更加高效个规范的落实供水管理 工作[9]。

与此同时, 智慧供水管理系统建设期间, 应把提升城 市供水管理的效率作为基本目标, 进一步升级和优化传统 的水务服务, 建设一个系统化、规范化和智能化的城市供 水服务系统与平台。

\section{2. 做好信息系统的建设工作}

信息数据资源系统的建设, 作为城市智慧水务系统建 设以及应用的要点, 仅有优先做好信息数据资源系统的建 设, 才能为智慧水务系统的更好运行和应用做保障 [10]。 城市供水系统建设中, 应用智慧水务系统, 不要单一的局 限在水务工程项目的建设中, 要重视信息资源系统的建设, 完善以往水务系统系统结构以及框架系统建设不足 [11]。 
具体来讲, 城市供水中建设智慧水务系统, 可以确保系统 安全以及稳定和有效运行, 进而建设更加完整的信息资源 管理体系以及系统结构, 以此为城市供水服务等工作提供 数据信息支持, 利于更好的做出决策。智慧水务系统建设 期间，应把互联共享、智慧化以及信息化建设作为目标以 及重点内容[12]。

\section{3. 了解智慧水务系统应用效益}

要想进一步推广和应用智慧水务系统, 要明确和了解 智慧水务系统带来的积极影响以及效益, 这样才能获得大 众的肯定, 普及和应用该系统。智慧水务系统带来的效益 包括以下几个不同方面:

其一, 建设智慧水务系统, 可以为城市以及社会的发 展带来明显的效益, 如可以提高城市供水作业的效率, 稳 定城市供水水质, 提供可靠的供水安全保障, 降低城市供 水管理的风险等等 $[13]$ 。

其二, 智慧水务系统能够提供智能化、便捷化和人性 化的城市供水服务。供水企业要创新以往水务系统, 大力 引进和应用新型技术, 建设更加安全与可靠的水务系统, 以此树立企业良好形象, 塑造良好企业形象, 使得大众更 加满意和信赖企业, 在获得大众认可的同时, 提高大众满 意度, 从而促进企业的发展, 进一步推动城市经济的全面 发展 $[14]$ 。

\section{5. 结论}

总的来讲, 智慧水务系统, 对城市的发展以及企业自 身的发展意义重大。因此, 企业要意识到当下社会城市发 展中智慧水务系统建设的意义与应用价值, 深入研究和分 析智慧水务系统, 做好智慧水务系统平台以及功能和信息 系统的建设工作, 及时完善和升级智慧水务系统, 以此落 实智能化和规范化以及精细化的服务, 建设更加全面和完 善的城市供水及服务平台。需要注意的是, 在智慧水务系 统建设和应用期间, 要尽量避免出现信息孤岛问题, 通过 建设统一化数据模型, 保证数据信息完整性与一致性, 这 样利于为管理、举措提供参考信息, 保证管理以及决策和 各项服务的水平与质量, 确保平台系统规范化运行, 发现 问题及时管控[15]。

\section{参考文献}

[1] 续青. 提高供水安全与效益的对策 [J]. 城镇供 水,2011,(01):96-102.

[2] 郭剑桥,田甜,张坤林.基于新技术的长江大保护智慧水务系 统应用[J].绿色科技,2020,(14):63-64.

[3] 顾天琪.浅析智慧水务系统在城市供水中的应用 [J]. 中国机 械,2020,(17):28-30.

[4] 谢善斌,袁杰,侯金霞.智慧水务信息化系统建设与实践 $[\mathrm{J}]$.给 水排水,2018,(04):134-140.

[5] 沈南.智慧水务系统在城市供水中的运用研究 [J].科技与创 新,2021,(07):158-159.

[6] 张新,刘芬,秦乾.浅谈智慧水务系统在城市供水中的应用 $[\mathrm{J}]$. 砖瓦世界,2019,(18):13-13.

[7] 崔子腾,吕福才, 马越.智慧水务系统在城市供水中的应用研 究[J].城市建设理论研究(电子版),2019,(12):181.

[8] 魏柯朋,钱爱君. 智慧水务系统在城市供水中的应用研究 [J]. 计算机产品与流通,2019,(02):96.

[9] 朱振华.智慧水务系统在城市供水中的应用研究[J].河南科 技,2019,(28):84-85.

[10] 杨满园.城市智慧水务大数据业务应用及其技术探究 [J].计 算机产品与流通,2019,(04):126-126.

[11] 廖兴波.智慧水务系统在城市供水中的应用[J].中国科技纵 横,2019,(04):126-126.

[12] 吴巍.智慧水务系统在城市供水中的应用 [J].中小企业管理 与科技(下旬刊),2019,(03):152-153.

[13] 黄艳. 智慧水务是未来水务的发展方向 [J]. 中国科技纵 横,2019,(06):16-17.

[14] 杨哲.智慧水务系统在城市供水中的应用 [J].科技创新导 报,2020,13(11):36-38.

[15] 刘佳星. 智慧水务建设需求探析 [J]. 商品与质 量,2016,(08):350-351. 